\title{
Re-addressing the 2013 consensus guidelines for the diagnosis of insulitis in human type 1 diabetes: is change necessary? Reply to Campbell-Thompson ML, Atkinson MA, Butler AE et al [letter]
}

\author{
Marcus Lundberg $^{1} \cdot$ Peter Seiron $^{1} \cdot$ Sofie Ingvast ${ }^{1} \cdot$ Olle Korsgren $^{1} \cdot$ Oskar Skog $^{1}$
}

Received: 22 December 2016 / Accepted: 6 January 2017 /Published online: 22 January 2017

(C) Springer-Verlag Berlin Heidelberg 2017

Keywords CD45 · Immunopathology · Inflammation · Insulitis $\cdot$ Islets $\cdot$ Macrophages $\cdot$ Pancreas $\cdot$ T cells $\cdot$ Type 1 diabetes $\cdot$ Type 2 diabetes

To the Editor: Although Campbell-Thompson et al did not approve of our revised definition of insulitis [1], we appreciate the reasoning and arguments put forward. However, we find it unfortunate that the authors affiliated with the 2013 consensus definition of insulitis [2] fail to see the predicaments with their report in light of our new data [3].

The pathoaetiology of type 1 diabetes remains undetermined and little is known about the role of the insulitic lesion in this process. While a few $\mathrm{T}$ cells present in the pancreas have been demonstrated to react to islet antigens in some individuals with type 1 diabetes [4-6], indication of mono- or oligoclonality remains lacking and most lymphocytes that are found in the islets are of unknown specificity [5]. In fact, the peculiar accumulation of T cells in the peri-islet area, with only few cells infiltrating the actual islet parenchyma, suggests that these cells are not part of a conventional cytotoxic response targeting the beta cells.

Regarding islet inflammation in type 2 diabetes, CampbellThompson et al claim that there are no data to support the proposition that this process plays a role in the pathogenesis of the disease and they suggest that the term 'insulitis' should not be used when referring to patients with type 2 diabetes.

Marcus Lundberg

marcus.lundberg@igp.uu.se

1 Department of Immunology, Genetics and Pathology, The Rudbeck Laboratory C11, Clinical Immunology, Uppsala University, Dag Hammarskjölds väg 20, 75185 Uppsala, Sweden
Here we refer to a recent publication by P. Marchetti [7], arguing a crucial role for islet inflammation as part of the pathoaetiology of type 2 diabetes. A consensus definition for determining the presence of islet inflammation in type 2 diabetes is currently lacking and a definition of 'insulitis' in type 2 diabetes has been requested [7].

Infiltrating immune cells are key to any definition of insulitis, and $\geq 15 \mathrm{CD} 45^{+}$cells in $\geq 3$ islets is what we and others [8-11] have interpreted as central to the consensus definition. The presence of pseudoatrophic islets, i.e. islets devoid of beta cells, is useful for determining whether a pancreas is from an individual with type 1 diabetes or not, but adds little information on why the beta cells were lost. As a requirement for the diagnosis of insulitis, the presence of pseudoatrophic islets makes the threshold level of CD45 cells in type 1 diabetes redundant, and precludes the diagnosis of insulitis in other patient groups, including most donors without diabetes but with diabetes-associated autoantibodies.

The authors of the letter [1] erroneously referred to our report by stating that four donors with recent-onset type 1 diabetes had $\geq 15 \mathrm{CD} 45^{+}$cells in $\geq 3$ islets. In fact, two of these donors had long-standing type 1 diabetes and one of them was without remaining insulin-positive cells. Pancreatitis and ongoing inflammation have frequently been reported in the exocrine pancreas of type 1 diabetic donors $[4,12,13]$ and from our report it can be deduced that these also occur in the pancreas of individuals with type 2 diabetes. When the original consensus definition was designed, the threshold level for insulitis was set at a level to distinguish it from the background cellular infiltration in non-diabetic donors. However, the consensus definition does not take into account elevations in background infiltrate resulting from inflammation in the exocrine pancreas [4, 12-14]. Well-preserved biopsies obtained from individuals with type 2 diabetes may serve as suitable controls to exclude this inflammatory background 
from the lymphocytic insulitis in type 1 diabetes and our revised definitions take into account this background inflammation. In our study, only the donors with recent-onset type 1 diabetes and remaining beta cells fulfilled our revised criteria of $\geq 15 \mathrm{CD}^{+}$cells in $\geq 3$ islets [3] and we urge the scientific community to carefully re-evaluate the term 'insulitis' to reflect an immunological event specifically present during ongoing beta cell destruction.

We agree fully that clarity is of paramount importance when defining insulitis and that the definition should be robust and applied rigorously. Since 2013, almost 50 published articles (according to Scopus [49; www.scopus.com/home.uri, accessed 12 January 2017] and Web of Science [45; http://wok. mimas.ac.uk, accessed 12 January 2017]) have cited the consensus definition. None have described all three criteria outlined in the letter by Campbell-Thompson et al [1] and only three original reports have used the consensus definition of $\geq 15$ $\mathrm{CD} 45^{+}$cells in $\geq 3$ islets $[3,11,15]$. Of these, two originate from our group $[3,15]$. Notably, in a recent publication [16] Campbell-Thompson et al used $\geq 6 \mathrm{CD}^{+}$cell in $\geq 3$ islets to define insulitis with reference to the consensus definition [2]. The lack of adherence to the consensus definition within the scientific community remains a problem and calls for a revision that is deemed worthwhile and adopted by scientists active in the field.

We are aware that our suggestion is inconvenient for some, but revision of the consensus definition of insulitis from 2013 [1] will hopefully have several important implications by: (1) allowing discrimination of the islet inflammation in type 1 diabetes from that in type 2 diabetes; (2) enabling discrimination of individuals with recent-onset type 1 diabetes from those with longstanding type 1 diabetes without ongoing beta cell destruction; and (3) having the potential to gain acceptance by the scientific community because of its usefulness as a tool for unravelling the aetiology of type 1 diabetes.

A common definition of insulitis is important, as it allows comparison between studies. However, the focus on insulitis should not cause us to neglect other morphological findings that may be equally, or more, important in the large ongoing efforts to describe the comprehensive pathology of type 1 and 2 diabetes. It is our common struggle to unravel the mechanisms behind these two diseases and eventually allow for the development of preventive therapies.

Acknowledgements We wish to thank everyone in the Nordic Network for Clinical Islet Transplantation who was involved in the procurement of pancreases and islets. We also give our deepest gratitude to all organ donors.

Funding Work in the authors' laboratories was supported by the PEVNET Study Group funded by the European Union's Seventh Framework Programme [FP7/2007-2013] under grant agreement number 261441 PEVNET, the Swedish Medical Research Council (K2015-54X12219-19-4), the Diabetes Wellness Foundation, the Family Ernfors
Foundation, the Novo Nordisk Foundation, the Âke Wiberg Foundation, the Tore Nilsson Foundation, the Swedish Diabetes Association, Gillbergska Stiftelsen, and Barndiabetesfonden. Human pancreatic biopsies and isolated islets were obtained from the Nordic Network for Clinical Islet Transplantation, supported by the Swedish national strategic research initiative Excellence of Diabetes Research in Sweden (EXODIAB) and the JDRF.

Duality of interests The authors declare that there is no duality of interest associated with this manuscript.

Contribution statement All authors were responsible for drafting the letter and revising it critically for important intellectual content. All authors approved the version to be published.

\section{References}

1. Campbell-Thompson ML, Atkinson MA, Butler AE et al (2017) Re-addressing the 2013 consensus guidelines for the diagnosis of insulitis in human type 1 diabetes: is change necessary? Diabetologia. doi:10.1007/s00125-016-4195-x

2. Campbell-Thompson ML, Atkinson MA, Butler AE et al (2013) The diagnosis of insulitis in human type 1 diabetes. Diabetologia 56:2541-2543

3. Lundberg M, Seiron P, Ingvast S, Korsgren O, Skog O (2017) Insulitis in human diabetes: a histological evaluation of donor pancreases. Diabetologia 60:346-353

4. Coppieters KT, Dotta F, Amirian N et al (2012) Demonstration of islet-autoreactive CD8 T cells in insulitic lesions from recent onset and long-term type 1 diabetes patients. J Exp Med 209:51-60

5. Michels AW, Landry LG, McDaniel KA et al (2016) Islet-derived CD4 T-cells targeting proinsulin in human autoimmune diabetes. Diabetes. doi:10.2337/db16-1025

6. Babon JA, DeNicola ME, Blodgett DM et al (2016) Analysis of self-antigen specificity of islet-infiltrating $\mathrm{T}$ cells from human donors with type 1 diabetes. Nat Med 22:1482-1487

7. Marchetti P (2016) Islet inflammation in type 2 diabetes. Diabetologia 59:668-672

8. Donath MY, Hess C, Palmer E (2014) What is the role of autoimmunity in type 1 diabetes? A clinical perspective. Diabetologia 57: 653-655

9. Battaglia M, Atkinson MA (2015) The streetlight effect in type 1 diabetes. Diabetes 64:1081-1090

10. Morgan NG, Leete P, Foulis AK, Richardson SJ (2014) Islet inflammation in human type 1 diabetes mellitus. IUBMB Life 66:723-734

11. Reddy S, Zeng N, Al-Diery H et al (2015) Analysis of peri-islet CD45-positive leucocytic infiltrates in long-standing type 1 diabetic patients. Diabetologia 58:1024-1035

12. Gepts W (1965) Pathologic anatomy of the pancreas in juvenile diabetes mellitus. Diabetes 14:619-633

13. Junker K, Egeberg J, Kromann H, Nerup J (1977) An autopsy study of the islets of Langerhans in acute-onset juvenile diabetes mellitus. Acta Pathol Microbiol Scand A Pathol 85:699-706

14. Rodriguez-Calvo T, Ekwall O, Amirian N, Zapardiel-Gonzalo J, von Herrath MG (2014) Increased immune cell infiltration of the exocrine pancreas: a possible contribution to the pathogenesis of type 1 diabetes. Diabetes 63:3880-3890

15. Wiberg A, Granstam A, Ingvast $\mathrm{S}$ et al (2015) Characterization of human organ donors testing positive for type 1 diabetes-associated autoantibodies. Clin Exp Immunol 182:278-288

16. Campbell-Thompson M, Fu A, Kaddis JS et al (2016) Insulitis and beta-cell mass in the natural history of type 1 diabetes. Diabetes 65 : $719-731$ 